\title{
Renal compensation to chronic hypoxic hypercapnia: downregulation of pendrin and adaptation of the proximal tubule
}

\section{Sophie de Seigneux, Hans Malte, Henrik Dimke, Jørgen Frøkiær, Søren Nielsen}

and Sebastian Frische

Am J Physiol Renal Physiol 292:F1256-F1266, 2007. First published 19 December 2006;

doi:10.1152/ajprenal.00220.2006

You might find this additional info useful...

This article cites 48 articles, 29 of which can be accessed free at:

http://ajprenal.physiology.org/content/292/4/F1256.full.html\#ref-list-1

This article has been cited by 3 other HighWire hosted articles

It Is Chloride Depletion Alkalosis, Not Contraction Alkalosis

Robert G. Luke and John H. Galla

JASN, February , 2012; 23 (2): 204-207.

[Abstract] [Full Text] [PDF]

Fluorescence isolation of mouse late distal convoluted tubules and connecting tubules:

effects of vasopressin and vitamin $\mathrm{D}_{3}$ on $\mathrm{Ca}^{2+}$ signaling

Marlene V. Hofmeister, Robert A. Fenton and Jeppe Praetorius

Am J Physiol Renal Physiol 2009; 296 (1): F194-F203.

[Abstract] [Full Text] [PDF]

High phenotypic intrafamilial variability in patients with Pendred syndrome and a novel duplication in the SLC26A4 gene: clinical characterization and functional studies of the mutated SLC26A4 protein

Laura Fugazzola, Valentina Cirello, Silvia Dossena, Simona Rodighiero, Marina Muzza,

Pierangela Castorina, Faustina Lalatta, Umberto Ambrosetti, Paolo Beck-Peccoz, Guido Bottà and Markus Paulmichl

Eur J Endocrinol, September , 2007; 157 (3): 331-338.

[Abstract] [Full Text] [PDF]

Updated information and services including high resolution figures, can be found at:

http://ajprenal.physiology.org/content/292/4/F1256.full.html

Additional material and information about AJP - Renal Physiology can be found at: http://www.the-aps.org/publications/ajprenal

This information is current as of July 11, 2012.

AJP - Renal Physiology publishes original manuscripts on a broad range of subjects relating to the kidney, urinary tract, and their respective cells and vasculature, as well as to the control of body fluid volume and composition. It is published 12 times a year (monthly) by the American Physiological Society, 9650 Rockville Pike, Bethesda MD 20814-3991. Copyright @ 2007 by the

American Physiological Society. ISSN: 1931-857X, ESSN: 1522-1466. Visit our website at http://www.the-aps.org/. 


\title{
Renal compensation to chronic hypoxic hypercapnia: downregulation of pendrin and adaptation of the proximal tubule
}

\author{
Sophie de Seigneux, ${ }^{1,2}$ Hans Malte, ${ }^{3}$ Henrik Dimke,,${ }^{1,2}$ \\ Jørgen Frøkiær, ${ }^{1,4}$ Søren Nielsen, ${ }^{1,2}$ and Sebastian Frische ${ }^{1,2}$ \\ ${ }^{1}$ The Water and Salt Research Center, ${ }^{2}$ Institute of Anatomy, and ${ }^{3}$ Zoophysiology, Department of Biological \\ Sciences, University of Aarhus; and ${ }^{4}$ Institute of Clinical Medicine, Aarhus University Hospital, Aarhus, Denmark
}

Submitted 16 June 2006; accepted in final form 6 December 2006

De Seigneux S, Malte H, Dimke H, Frøkiær J, Nielsen S, Frische S. Renal compensation to chronic hypoxic hypercapnia: downregulation of pendrin and adaptation of the proximal tubule. Am J Physiol Renal Physiol 292: F1256-F1266, 2007. First published December 19, 2006; doi:10.1152/ajprenal.00220.2006.-The molecular basis for the renal compensation to respiratory acidosis and specifically the role of pendrin in this condition are unclear. Therefore, we studied the adaptation of the proximal tubule and the collecting duct to respiratory acidosis. Male Wistar-Hannover rats were exposed to either hypercapnia and hypoxia $\left[8 \% \mathrm{CO}_{2}\right.$ and $13 \%$ $\mathrm{O}_{2}$ (hypercapnic, $n=6$ ) or normal air (controls, $n=6$ )] in an environmental chamber for 10 days and were killed under the same atmosphere. In hypercapnic rats, arterial $\mathrm{pH}$ was lower than controls ( $7.31 \pm 0.01$ vs. $7.39 \pm 0.01, P=0.03)$, blood $\mathrm{HCO}_{3}^{-}$concentration was increased $(42 \pm 0.9$ vs. $32 \pm 0.24 \mathrm{mM}, P<0.001)$, arterial $\mathrm{PCO}_{2}$ was increased $(10.76 \pm 0.4$ vs. $7.20 \pm 0.4 \mathrm{kPa}, P<0.001)$, and plasma chloride concentration was decreased (92.2 \pm 0.7 vs. $97.2 \pm$ $0.5 \mathrm{mM}, P<0.001)$. Plasma aldosterone levels were unchanged. In the proximal tubule, immunoblotting showed an increased expression of sodium/bicarbonate exchanger protein $(188 \pm 22$ vs. $100 \pm 11 \%$, $P=0.005)$, confirmed by immunohistochemistry. Total $\mathrm{Na} / \mathrm{H}$ exchanger protein expression in the cortex was unchanged by immunoblotting (119 \pm 10 vs. $100 \pm 11 \%, P=0.27)$ and immunohistochemistry. In the cortex, the abundance of pendrin was decreased (51 \pm 9 vs. $100 \pm 7 \%, P=0.003$ ) by immunoblotting. Immunohistochemistry revealed that this decrease was clear in both cortical collecting ducts (CCDs) and connecting tubules (CNTs). This demonstrates that pendrin expression can be regulated in acidotic animals with no changes in aldosterone levels and no external chloride load. This reduction of pendrin expression may help in redirecting the CNT and CCD toward chloride excretion and bicarbonate reabsorption, contributing to the increased plasma bicarbonate and decreased plasma chloride of chronic respiratory acidosis.

cortical collecting duct; chloride regulation; intercalated cells; bicarbonate

HYPERCAPNIA AND CONSECUTIVE respiratory acidosis with concomitant hypoxemia are well-known pathological conditions observed in different disease states. Hypercapnia is also encountered in the care of acute respiratory distress syndrome and is therefore not rare in a clinical setting (20). Hypercapnia induces acidosis of the respiratory type, due to a rise in blood $\mathrm{PCO}_{2}$ which will displace the $\mathrm{CO}_{2} \rightleftharpoons \mathrm{HCO}_{3}^{-}+\mathrm{H}^{+}$equilibrium, leading to a decrease in blood $\mathrm{pH}$. In the early phase of hypercapnia (the initial rise in $\mathrm{PCO}_{2}$ ), extrarenal factors are very important to buffer the $\mathrm{pH}(14)$. This is in contrast to chronic elevation of $\mathrm{PCO}_{2}$, where the kidney is the

Address for reprint requests and other correspondence: S. Frische, The Water and Salt Research Center, Institute of Anatomy, Bldg. 1234, Univ. of Aarhus, DK-8000 Aarhus C, Denmark (e-mail: sfri@ana.au.dk). major player in stabilizing $\mathrm{pH}$ (37). However, the molecular mechanisms by which the kidney compensates a chronic respiratory acidosis are incompletely understood.

In the proximal tubule, $70-80 \%$ of the filtered bicarbonate is reabsorbed, mainly via the apical $\mathrm{Na} / \mathrm{H}$ exchanger (NHE3) and, to a lesser extent, via an apical vacuolar proton pump (2, $3,15,28)$. Most studies suggest that adaptation of proximal tubular transport is important for renal compensation during prolonged respiratory acidosis $(5,32,39)$. This occurs via activation of the sodium/proton exchanger NHE3 and the sodium/bicarbonate exchanger NBCe1 $(32,33,39)$. However, the importance of the increased proximal tubular bicarbonate reabsorption has been questioned $(34,48)$.

In addition to the proximal tubule, the collecting duct plays a major role in the final acidification of the urine during acid-base challenges by modulations of intercalated cell transport mechanisms $(27,40,41)$. The importance of these cells is clear in metabolic acidosis. In this situation, an increase in the activity of the proton pump occurs in conjunction with a decrease in abundance of the anion exchanger pendrin, resulting in a decreased excretion of bicarbonate by the cortical collecting duct and in a further acidification of the urine $(13,45)$.

Pendrin is a bicarbonate/chloride exchanger located in the apical domain of the type B and non-A non-B intercalated cells (19). Traditionally, intercalated cells are considered to be primarily acid-base regulators, and therefore pendrin was initially thought to be involved in the maintenance of the acidbase status since its expression is regulated in metabolic acidosis and alkalosis $(13,45)$. However, the pendrin null mice presented with no acid-base disturbance during basal conditions (31), and evidence has been presented that pendrin function is involved in processes which may mediate mineralocorticoid-induced hypertension (43). Furthermore, as many of the animal models involving metabolic acidosis or alkalosis imply major changes in chloride intake, which by themselves appear to influence pendrin regulation $(30,42,46)$, the exact role of pendrin in acid-base physiology is still to be determined. The influence of respiratory acidosis on pendrin regulation is unknown and is interesting, as this condition represents a pure primary acid-base disturbance with no load of electrolytes superimposed. Respiratory acidosis is usually observed with concomitant hypoxemia. Accordingly, we designed the experimental conditions to mimic this situation and studied the renal adaptation to respiratory acidosis.

The costs of publication of this article were defrayed in part by the payment of page charges. The article must therefore be hereby marked "advertisement" in accordance with 18 U.S.C. Section 1734 solely to indicate this fact. 


\section{METHODS}

Experimental protocol. Experiments were performed using male Wistar-Hannover rats (160-180 g, Dept. of Physiology, Univ. of Aarhus, Aarhus, Denmark). The animal experiments were performed following the Danish legislation on animal experiments and according to license 2005/516-1032 for use of experimental animals issued by the Danish Ministry of Justice.

Chronic normobaric hypercapnia and hypoxia. Rats were placed in normal cages inside an airtight Plexiglas chamber. The chambers were closed, and the internal $\mathrm{PO}_{2}, \mathrm{PCO}_{2}$, temperature, and relative humidity (RH) were controlled. Air conditioning devices were attached to each box and the RH was maintained at $45 \%$ in each cage and the temperature between 20 and $22^{\circ} \mathrm{C}$. Rats were allowed free access to pellet food (Altromin 1320) and tap water during the entire experiment. Pair feeding was not performed due to the obligation of keeping the chamber closed during the experiment. Food intake, however, was recorded at the end of the experiment and was altogether lower in the hypercapnic group (478 $\mathrm{g}$ in total for hypercapnic rats vs. $614 \mathrm{~g}$ for controls during the 10 days for all rats).

In the hypercapnic group, the chamber was kept closed, allowing for a progressive rise in $\mathrm{PCO}_{2}$ and decline in $\mathrm{PO}_{2}$ due to the rats' metabolism. $\mathrm{PCO}_{2}$ and $\mathrm{PO}_{2}$ in the chamber were monitored and recorded continuously on a computer. The sensors for $\mathrm{O}_{2}$ (Servomex $570 \mathrm{~A}$ ) and for $\mathrm{CO}_{2}$ (Qubit S 153) were calibrated on a daily basis. When the desired level of $\mathrm{CO}_{2}$ was reached, a Labview computer program turned on an air pump (Reciprotor $506 \mathrm{R}$ ), which drove air out of the chambers. By pressure equilibrium, the equivalent amount of fresh air would then enter the box through a 2-m-long (to impair back-diffusion) gastight tube. The pump was set to be turned off when a value $<8.3 \% \mathrm{CO}_{2}$ was recorded and was automatically turned on when the $\mathrm{CO}_{2}$ reached $8.3 \%$ inside the Plexiglas box. Due to dead spaces and various other delays, this setting allowed maintenance of the $\mathrm{CO}_{2}$ percentage within $8.3 \pm 0.5 \%$. Due to the metabolism of the rats, the oxygen concentration decreased in the chambers to $\sim 13 \%$, mimicking respiratory failure. Control rats were placed in the same type of airtight Plexiglas chamber controlled in the same way, but the limit for $\mathrm{CO}_{2}$ was set at $0.2 \%$, resulting in an almost normal atmosphere in the chamber. Dehumidification and air mixing were established in parallel in the control rats. After 10 days of exposure to this environment, the rats were killed.

Anesthesia and sampling of blood and tissue. To minimize the changes in composition of inspired air during the time of death, air exiting the hypercapnic chamber was collected in airtight "Douglas" bags during the last day. When the hypercapnic rats were euthanized, this air mixed with isoflurane was used in the evaporative anesthesia system (Forane, Abbott Laboratories, Gentofte, Denmark). For control rats, normal room air mixed with isoflurane was used. After anesthesia, a large laparotomy was performed and the abdominal aorta was cannulated. Blood was collected by a three-way valve system. Subsequently, the right renal artery was clamped and the right kidney was removed, dissected into zones [cortex and outer stripe of outer medulla (cortex/OSOM), inner stripe of outer medulla (ISOM) and inner medulla (IM)], and processed for immunoblotting as described below. The left kidney was fixed by retrograde perfusion as described below.

Plasma and blood values. One aliquot of the arterial blood sample was analyzed immediately for $\mathrm{pH}, \mathrm{PCO}_{2}, \mathrm{PO}_{2}, \mathrm{Cl}^{-}, \mathrm{Ca}^{2+}$, and lactate in an ABL system 615 (Radiometer, Copenhagen, Denmark). Blood bicarbonate and base excess were calculated with the ABL 615 software from the measured parameters. The remaining blood was centrifuged for $15 \mathrm{~min}$ at 4,000 $\mathrm{g}$ to remove blood cells, and the plasma was analyzed for sodium, potassium, and creatinine using a Vitros 950 (Johnson\&Johnson). Osmolality was measured with an automatic cryoscopic osmometer (Osmomat 030, Gonotech). Plasma aldosterone concentrations were determined using a commercially available radioimmunoassay kit (Coat-A-Count, Diagnostic Products, Los Angeles, CA).

Primary antibodies. The following previously characterized antibodies were used: rabbit polyclonal anti-NBCE1 (1159AP) against rat NBCE1 (26); rabbit polyclonal anti-NHE3 L546 against rat NHE3 $(11,16)$ (kind gift from Dr. M. Knepper, LKEM, National Institutes of Health, Bethesda, MD) for Western blotting and immunohistochemistry; rabbit polyclonal anti-NHE3C00 raised against a peptide similar to the peptide used to generate L546 for immunohistochemistry (kind gift from Alicia McDonough, Univ. of Southern California Keck School of Medicine, LA, CA) (47); rabbit polyclonal anti-V1ATPase B1 subunit (H7659) against rat V1-ATPase B1 subunit (4); rabbit polyclonal anti-pendrin (RA3466/2671) against mouse pendrin, previously characterized in rats (19); and rabbit polyclonal anti- $\alpha$ ENaC subunit (6) (kind gift from Dr. B. C. Rossier, Dept. of Pharmacology, Univ. of Lausanne, Lausanne, Switzerland). Rabbit polyclonal anti- $\beta$-ENaC (5161) and anti- $\gamma$-ENaC (5163) against rat $\beta$ - and $\gamma$-ENaC were developed against peptides with similar amino acid sequences as previously used (24). Immunoblotting and immunohistochemistry revealed identical patterns compared with previously developed antibodies to similar peptides. Peptide preabsorption on immunoblotting and immunohistochemistry revealed specific abatable bands and labeling (data not shown). Moreover, immunohistochemistry and immunoblotting using the antibodies showed an upregulation of the proteins in samples from DDAVP-treated Brattleboro rats as demonstrated previously (7) (data not shown). Polyclonal rabbit anti-aquaporin-2 (AQP2 H7661) against rat AQP2 was developed against the same sequence as previously used (29). Immunoblotting and immunohistochemistry using this antibody revealed identical patterns compared with previously developed antibodies to similar peptides. Peptide preabsorption on immunoblotting and immunohistochemistry revealed specific abatable bands and labeling (data not shown).

A commercially available mouse monoclonal antibody against rat calbindin D-28K (Research Diagnostics, Flanders, NJ) was used.

Semiquantitative immunoblotting. The dissected renal cortex/ OSOM, ISOM, and inner medulla were homogenized (Ultra-Turrax T8 homogenizer, IKA Labortechnik, Staufen, Germany) in ice-cold isolation solution containing $0.3 \mathrm{M}$ sucrose, $25 \mathrm{mM}$ imidazole, $1 \mathrm{mM}$ EDTA, $8.5 \mu \mathrm{M}$ leupeptin, and $1 \mathrm{mM}$ Pefabloc at $\mathrm{pH} \mathrm{7.2.} \mathrm{The}$ homogenates were centrifuged at $4,000 \mathrm{~g}$ for $15 \mathrm{~min}$ at $4^{\circ} \mathrm{C}$ to remove whole cells and larger organelles, and the supernatant was collected and kept on ice. All samples were heated to $65^{\circ} \mathrm{C}$ for $15 \mathrm{~min}$ after addition of SDS containing sample buffer and then stored at $-20^{\circ} \mathrm{C}$. Immunoblotting was performed as previously described (13). Results are presented as densities relative to the control group.

Fixation of rat kidneys and immunohistochemistry. A needle connected by tubing to PBS and fixative reservoirs pressurized to 160 $\mathrm{mmHg}$ with air was inserted in the abdominal aorta of isofluraneanesthetized rats, and the inferior caval vein was cut to establish an outlet. After a 15-s perfusion with cold PBS (pH 7.4), the kidney was perfused with cold $3 \%$ paraformaldehyde in $0.1 \mathrm{M}$ cacodylate buffer ( $\mathrm{pH}$ 7.4) for $3 \mathrm{~min}$. The kidney was removed and sectioned into 2- to 3 -mm transverse sections and immersion fixed for additionally $1 \mathrm{~h}$, followed by $3 \times 10$-min washes with $0.1 \mathrm{M}$ cacodylate buffer, $\mathrm{pH}$ 7.4. Immunohistochemistry was performed as previously described (13).

Cell counting. Counting of pendrin-positive cells relative to total number of nuclei in CCDs and CNTs was performed, as described in detail (13), with the modification that nuclei were labeled using a nuclear counterstain, TO-PRO-3 iodide (642/661, Invitrogen, Molecular Probes). The fraction of pendrin-positive cells in hypercapnic rats was normalized to the fraction of pendrin-positive cells in control rats.

Immunoelectron microscopy. For immunoelectron microscopy, small pieces of kidney cortex were cut from slices of fixed kidney (see above), cryoprotected in $2.3 \mathrm{M}$ sucrose, and frozen in liquid nitrogen and prepared as described previously (13). 
Table 1. Blood parameters after 10-day exposure to hypercapnia/hypoxia

\begin{tabular}{|c|c|c|}
\hline & $\begin{array}{l}\text { Control } \\
(n=6)\end{array}$ & $\begin{array}{l}\text { Hypercapnia-Hypoxemia } \\
\qquad(n=6)\end{array}$ \\
\hline Arterial pH & $7.39 \pm 0.02$ & $7.33 \pm 0.04 *$ \\
\hline \multicolumn{3}{|l|}{ Arterial $\mathrm{PCO}_{2}$} \\
\hline $\mathrm{kPa}$ & $7.20 \pm 0.2$ & $10.76 \pm 0.4 \dagger$ \\
\hline $\mathrm{mmHg}$ & $54 \pm 2$ & $81 \pm 3 \dagger$ \\
\hline \multicolumn{3}{|l|}{ Arterial $\mathrm{PO}_{2}$} \\
\hline $\mathrm{kPa}$ & $12.51 \pm 0.8$ & $7.79 \pm 0.5 \dagger$ \\
\hline $\mathrm{mmHg}$ & $94 \pm 6$ & $58 \pm 4 \dagger$ \\
\hline $\mathrm{HCO}_{3}{ }^{-}, \mathrm{mmol} / 1$ & $32 \pm 0.24$ & $42 \pm 0.9 \dagger$ \\
\hline Base excess, mmol/1 & $7.1 \pm 0.3$ & $15.2 \pm 0.8 \dagger$ \\
\hline Saturation of oxygen, $\%$ & $95 \pm 2.6$ & $76 \pm 3.6^{*}$ \\
\hline \multicolumn{3}{|l|}{ Sodium, $\mathrm{mmol} / \mathrm{l}$} \\
\hline $\mathrm{ABL}$ & $137.8 \pm 0.4$ & $139.8 \pm 0.3^{*}$ \\
\hline FP & $135.7 \pm 0.3$ & $137.7 \pm 0.3^{*}$ \\
\hline \multicolumn{3}{|l|}{ Potassium, mmol/1 } \\
\hline ABL & $4.5 \pm 0.4$ & $4.3 \pm 0.1$ \\
\hline FP & $4.8 \pm 0.2$ & $4.2 \pm 0.1 *$ \\
\hline Chloride, $\mathrm{mmol} / \mathrm{l}$ & $97.2 \pm 0.5$ & $92.2 \pm 0.7 \dagger$ \\
\hline Calcium, mmol/l & $1.43 \pm 0.01$ & $1.44 \pm 0.02$ \\
\hline Lactate, mmol/1 & $2.18 \pm 0.22$ & $1.88 \pm 0.26$ \\
\hline Creatinine, $\mu \mathrm{mol} / 1$ & $6.5 \pm 1.5$ & $9.2 \pm 1.2$ \\
\hline Osmolarity, mOsm & $300 \pm 3$ & $302 \pm 1$ \\
\hline Aldosterone, $\mathrm{pg} / \mathrm{ml}$ & $513 \pm 82$ & $508 \pm 187$ \\
\hline
\end{tabular}

Values are means \pm SE. $n$, No. of rats; ABL, measured via the ABL 615 system; FP, measured in purified plasma using flame photometry. ${ }^{*} P<0.05$, $\dagger P<0.001$.

Evaluation of pendrin subcellular localization by immunoelectron microscopy. We evaluated the subcellular localization of pendrin in pendrin-positive cells by electron microscopy. Briefly, we identified a minimum of six pendrin-positive cells in the CNT and in the CCD of three animals in each group (total number of cell counted: 106 pendrin-positive cells). The cells were picked randomly as they were encountered during electron microscopy. Cells were selected for quantification if they were well preserved, showing a well-defined nucleus and organelles. Digital pictures were acquired at $\times 22,000$ magnification on a FEI Morgagni electron microscope operating at 80 $\mathrm{kV}$ using the Multiple Image Alignment (MIA) function of AnalySIS software. Each cell was imaged by merging 25 single images into one MIA-image. In AnalySIS software, the "touch-count" function was used, and each gold particle was manually identified and classified as either being localized to the apical plasma membrane (within $30 \mathrm{~nm}$ ) or in the cytoplasm of the pendrin-positive cell. To quantitatively assess the subcellular localization of pendrin, we calculated the ratio of the plasma membrane-associated gold particles to the total number of gold particles counted in the same cell. For each animal, the average of this ratio was calculated separately for cells from CNT and $\mathrm{CCD}$, and the mean in each group $(n=3)$ was then computed and analyzed statistically

Statistical analyses. Values are presented as means \pm SE. Comparisons between two groups were made by an unpaired $t$-test. $P$ values $<0.05$ were considered significant.

\section{RESULTS}

Plasma $\mathrm{pH}, \mathrm{Cl}^{-}$, and $\mathrm{PO}_{2}$ were reduced, whereas plasma $\mathrm{PCO}_{2}$ was increased in chronic hypoxic hypercapnia. At the time of death, hypercapnic rats presented with a significant decrease in their blood $\mathrm{pH}$ compared with the control group $(P=0.037)$ (Table 1$)$. This decrease in $\mathrm{pH}$ was consecutive to a marked increase in arterial $\mathrm{PCO}_{2}$ levels $(P<0.001)$ despite a concomitant rise in bicarbonate levels $(P<0.001)$ (Table 1$)$. The base excess was markedly increased in the treated group compared with the control group $(P<0.001)$. There was also a decrease in arterial $\mathrm{Po}_{2}$ in the hypercapnic group $(P<0.001)$. Using the ABL system, the plasma concentration of chloride was significantly decreased in the hypercapnic animals $(P<$ $0.001)$, whereas the plasma concentration of sodium was slightly increased $(P<0.05)$ and potassium was unchanged $(P=0.28)$. Using pure plasma and flame photometry, however, plasma potassium was slightly decreased $(P<0.05)$. Plasma osmolality and aldosterone were not different between the groups $(P=0.5$ and $=0.9)$ and there was no difference in plasma lactate between the groups $(P=0.4)$.

In the proximal tubule, NHE3 abundance was unchanged and NBCel abundance was increased. The total abundance of sodium/proton exchanger NHE3 was assessed in the kidney cortex. By semiquantitative immunoblotting, there was no change in the expression of the transporter in the cortex/OSOM $(P=0.27)$ (Fig. 1). This was confirmed by light microscopy, where an unchanged abundance of NHE3 in proximal tubules was observed using the $\mathrm{C} 00$ antibody (Fig. 2, $A$ and $B$ ). The L546 antibody showed identical results to C00 (data not shown). As NHE3 is situated in the apical domain of the proximal tubular cells of both control and treated rats, we were not able to distinguish changes in subcellular localization (Fig. 2, $A$ and $B$ ) with the resolution of immunoperoxidase microscopy, although this does exclude trafficking over short distances within the labeled area of the brush border. NHE3 labeling in the cortical and medullary thick ascending limb was also not modified, in agreement with an unchanged abundance of NHE3 in the ISOM by Western blotting (data not shown).

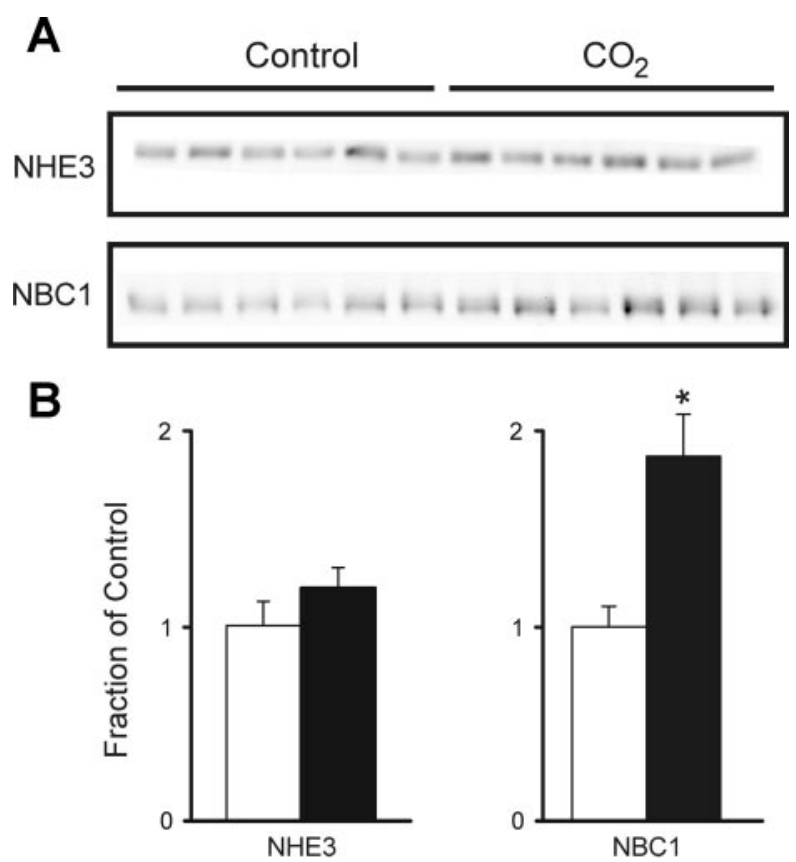

Fig. 1. Semiquantitative immunoblotting of homogenized rat kidney tissue from the cortex and outer stripe of the outer medulla obtained from control and hypercapnic rats. $A$ : immunoblot of samples from control $(n=6)$ and hypercapnic $(n=6)$ rats incubated with anti-Na/H exchanger (NHE3) antibody showing a distinct band at $\sim 87 \mathrm{kDa}$ and with sodium/bicarbonate exchanger (NBCe1) antibody showing a distinct band at $\sim 140 \mathrm{kDa}$. $B$ : densitometric analysis showed that the abundance of $\mathrm{NBCe} 1$ in hypercapnic rats (filled bars) was significantly increased $(P=0.005)$ compared with control rats (open bars), whereas NHE3 abundance was unchanged $(P=0.27)$. 


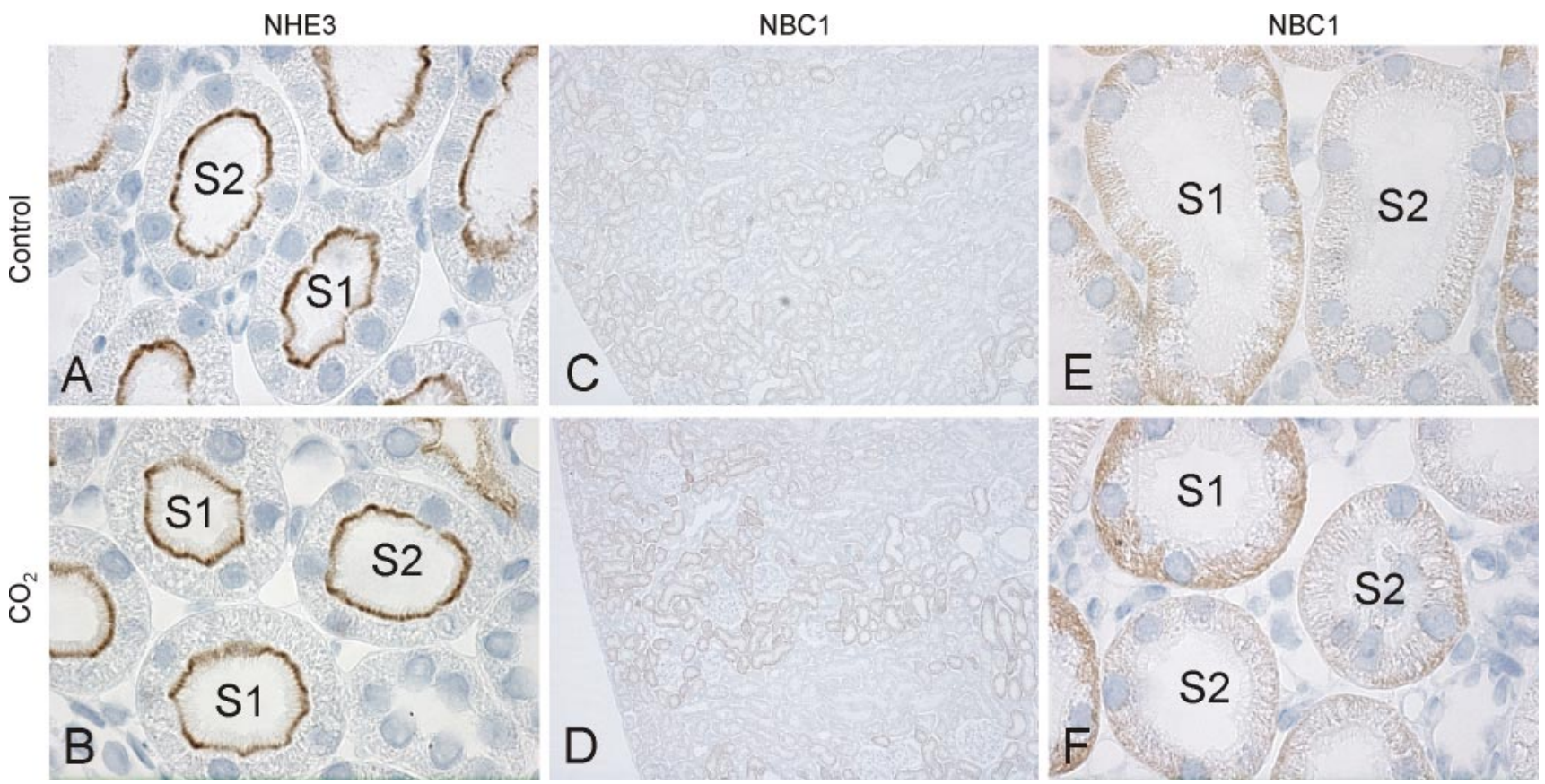

Fig. 2. Representative images of rat kidney sections labeled for NHE3 in control rats $(A)$ and hypercapnic rats $(B)$ and for NBCe1 in control rats at low $(C)$ and high $(E)$ magnification and in hypercapnic rats at low $(D)$ and high $(F)$ magnification. No difference in abundance of NHE3 was apparent between the groups $(A$ and $B)$. The distribution of NBCe1 labeling appeared similar in both groups but was globally more intense in hypercapnic rats $(D$ and $F)$. The increase in hypercapnic rats seemed to occur both in $\mathrm{S} 1$ and $\mathrm{S} 2$ segments $(E$ and $F)$.

As NBCe1 provides the main basolateral exit for bicarbonate in the proximal tubule, the relative change in abundance of this protein was also determined by semiquantitative immunoblotting. The abundance of NBCe1 was increased in the rats exposed to hypercapnia as assessed by immunoblotting (188 \pm $22 \%$ in hypercapnic rats against $100 \pm 11 \%$ in control rats, $P=0.005$ ) (Fig. 1, $A$ and $B$ ). Immunohistochemistry for this transporter confirmed an increase in NBCe1 expression, apparent as a relative increase in labeling intensity in the basolateral part of the proximal tubule in hypercapnic rats (Fig. 2, $C-F$ ). It is also known that $\mathrm{NBCe} 1$ is distributed unequally along the proximal tubule, being highly expressed in S1, less in S2, and probably not in S3 of rat proximal tubule (35). Subsegments of the proximal tubule were identified according to their localization and morphological criteria, such as the height of the brush border and the infoldings of the basolateral membrane (25). NBCe1 labeling was present in S1 and S2 in both groups, and was not visible in S3. We could not ascertain the increase in abundance to only one of the segments as both S1 and S2 appeared generally stronger in hypercapnic animals, although a variation in intensities between nephrons was visible. Again, by the resolution of light microscopy we could not assess modifications in subcellular localization of the protein (Fig. 2, $E$ and $F$ ).

Pendrin abundance was markedly downregulated in the cortical CNT and CCD of hypercapnic rats. Pendrin protein abundance was clearly decreased in rats exposed to hypercapnic conditions compared with controls, as assessed by semiquantitative immunoblotting ( $51 \pm 9 \%$ in hypercapnic rats vs. $100 \pm 7 \%$ in control rats, $P=0.003$ ) (Fig. 3). This was confirmed by immunohistochemistry, which demonstrated an overall decrease in the intensity of labeling in hypercapnic rats and an average decrease in the size of cells showing immuno- reactivity for pendrin (Fig. 4, $A$ and $B$ ). These changes were apparent both in the cortical labyrinth, which encloses both CCDs and CNTs, and in the straight segment of the collecting duct in medullary rays (Fig. $4, C-F$ ). Laser confocal microscopy of sections labeled for both calbindin-28K (marker to distinguish between CNT and CCD) and pendrin confirmed
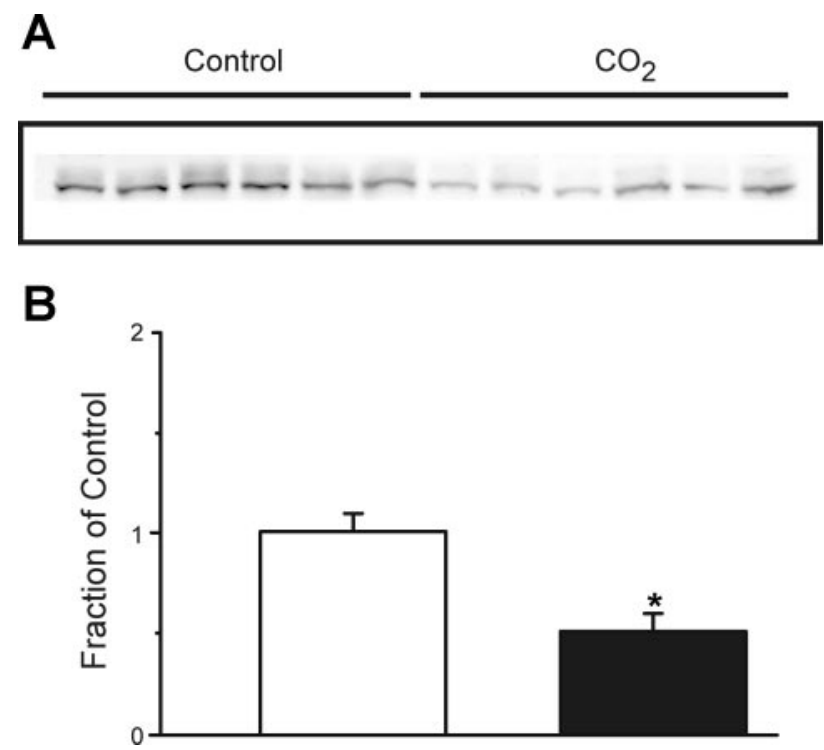

Fig. 3. Semiquantitative immunoblotting of homogenized rat kidney tissue from the cortex and outer stripe of the outer medulla (OSOM) obtained from control and hypercapnic rats. A: immunoblot of samples from control $(n=6)$ and hypercapnic $(n=6)$ rats incubated with anti-pendrin antibody showing a distinct band at $\sim 127 \mathrm{kDa}$. $B$ : densitometric analysis revealed a significant reduction of pendrin abundance $\left({ }^{*} P=0.003\right)$ in hypercapnic rats (filled bar) compared with control rats (open bar). 


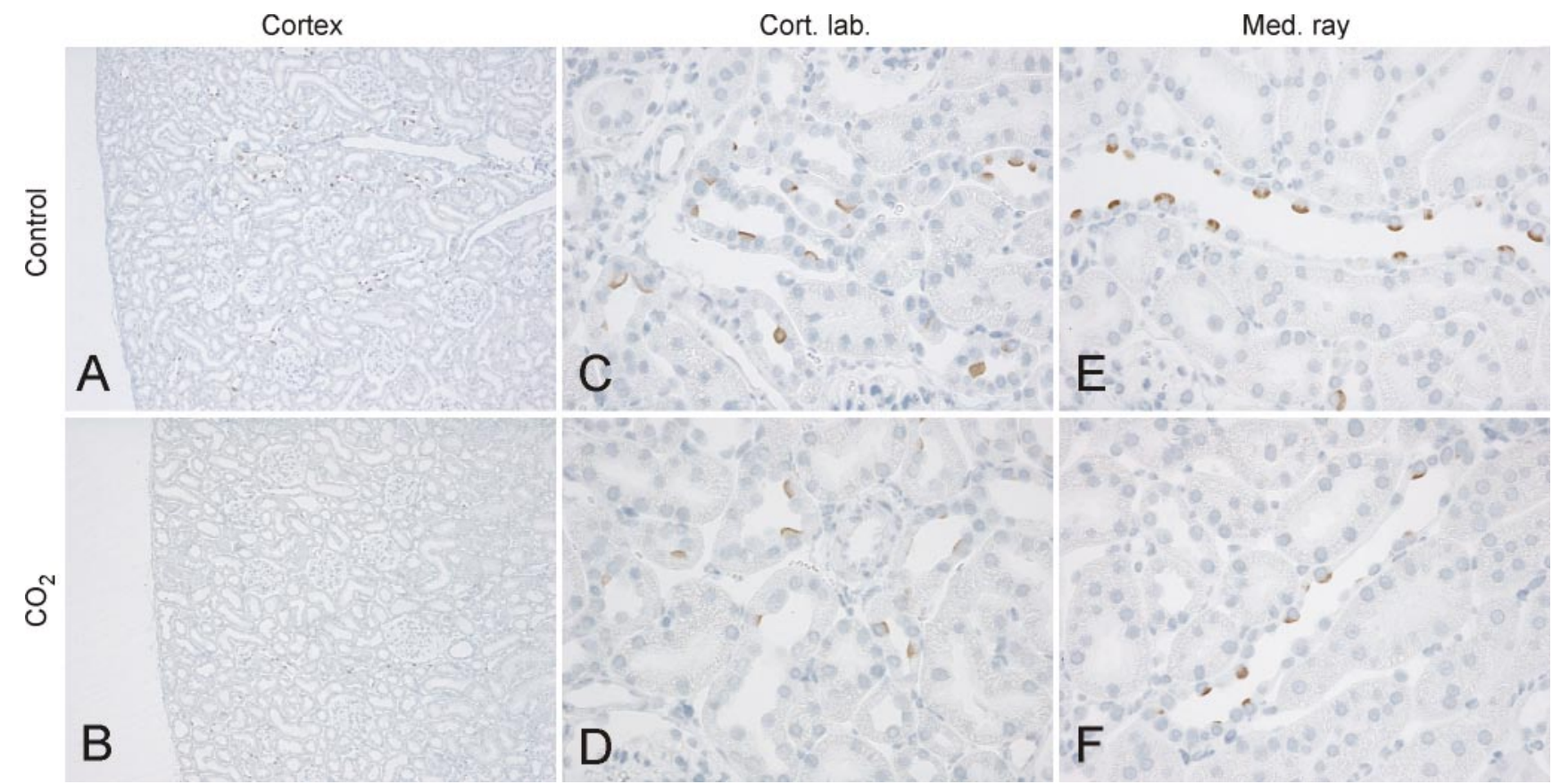

Fig. 4. Representative micrographs showing immunohistochemical localization of pendrin in sections of paraffin-embedded kidneys from control rats ( $A$, $C$, and $E$ ) and hypercapnic rats $(B, D$, and $F)$. At low magnification, the labeling in hypercapnic rats $(B)$ appeared less abundant than in control rats $(A)$. At higher magnification, pendrin labeling was seen in the apical part of intercalated cells in cortical labyrinth $(C$ and $D)$ and medullary rays $(E$ and $F)$ in both hypercapnic $(D$ and $F)$ and control rats $(C$ and $E$ ). The labeling intensity was decreased in hypercapnic rats in both medullary rays $(F)$ and cortical labyrinth $(D)$ compared with control rats $(C$ and $E)$. Both the intensity of the labeling and the overall size of the cells were decreased in hypercapnic rats $(D$ and $F)$ compared with controls $(C$ and $E)$.

Fig. 5. Representative micrographs showing double immunofluorescence labeling for pendrin and calbindin in connecting tubule (CNT) and cortical collecting duct (CCD) in sections of paraffin-embedded kidneys. CNTs were positively labeled by calbindin (insets, $A$ and $B$ ), whereas CCDs were less or not labeled by calbindin (insets, $C$ and $D$ ). The labeling intensity for pendrin was lower in hypercapnic rats both in CNTs $(C)$ and in CCDs $(D)$ compared with control CNTs $(A)$ and CCDs $(B)$.

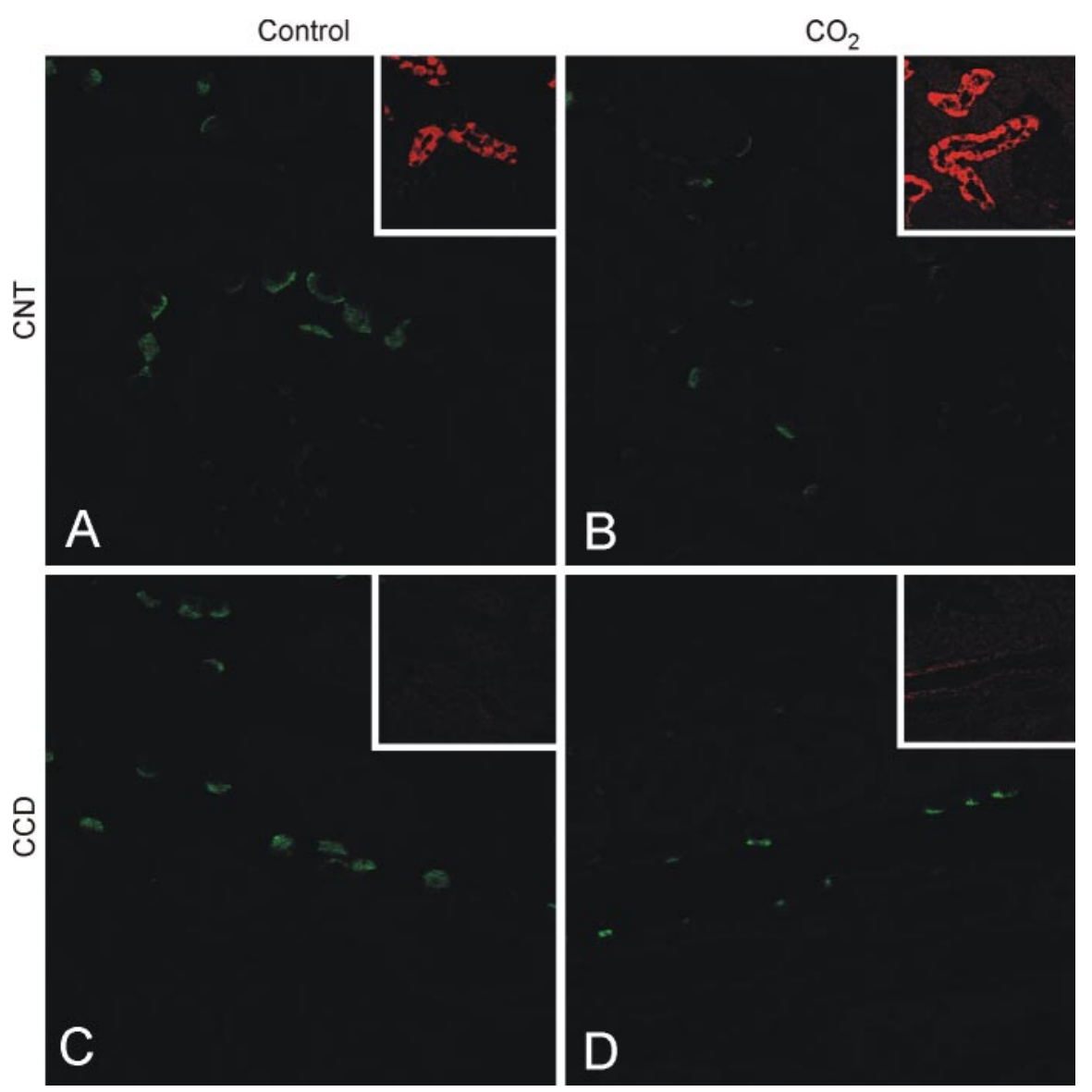


that the decrease in abundance was evident in both the CNTs and the CCDs (Fig. 5). Moreover, we counted the pendrinpositive cells relative to the number of nuclei in five CCDs and CNTs from each animal of the two groups using sections labeled for both pendrin and calbindin. The total number of counted cells in the CNTs was 613 in controls and 647 in hypercapnic rats. The total number of counted cells in CCDs was 846 in control rats and 1,073 in hypercapnic rats. The fraction of pendrin-positive cells was decreased in both CCDs and CNTs of hypercapnic rats compared with controls, although significance was reached $(P=0.002)$ only in CCDs (Fig. 6). The $P$ value in CNTs was 0.06 , which indicates a very likely decrease in pendrin-positive cells also in CNTs, although it did not reach our significance criteria. The lower fraction of pendrin-positive cells in hypercapnic animals could be due to either a decrease in the number of type $B$ and non- $A$ non- $B$ intercalated cells or to a decrease in pendrin expression in the cells, leading to a decrease in the number of cells expressing pendrin at detectable levels.

Pendrin subcellular localization appeared unchanged. By light microscopy, considerable cell-to-cell heterogeneity of the subcellular repartition of pendrin was evident in control and treated rats (Figs. 4 and 5), and no distinct pattern of trafficking

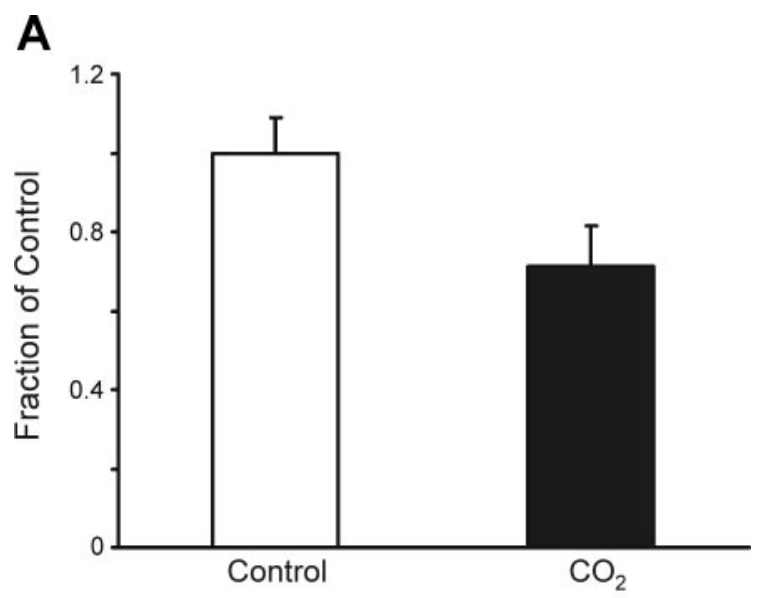

B

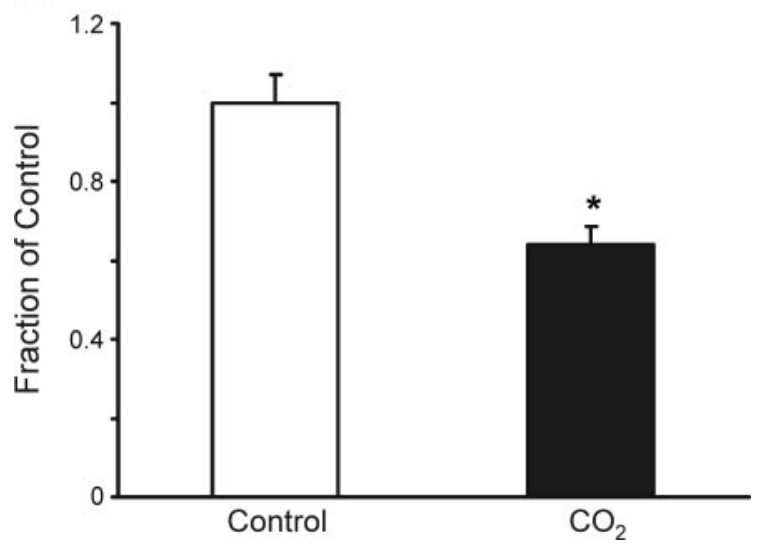

Fig. 6. The fraction of epithelial cells in CNT $(A)$ and CCD $(B)$ from control (open bars) and hypercapnic (filled bars) rats that exhibited immunofluorescent reactivity for pendrin. In $\mathrm{CNT}$, the reduction in the hypercapnic group to $71 \%$ of the control value was not statistically significant $(P=0.06)$. In CCD, the reduction in the hypercapnic group to $64 \%$ of the control value was statistically significant $(* P=0.002)$. could be ascertained to any of the groups. We therefore performed immunogold electron microscopy of tissue from the cortex of three rats in each group. We addressed here the whole population of cells showing immunoreactivity for pendrin. In the rat, this population is composed of type $\mathrm{B}$ intercalated cells and non-A non-B cells, the latter being present mostly in the CNT (18). In both groups, pendrin was located in the apical membrane and in intracellular membranous structures, predominantly in the apical part of the cells (Fig. 7). The ratio of the number of gold particles in the apical membrane divided by the total number of gold particles in the cell was calculated in a minimum of six cells from both the CNT and the CCD per animal. In neither the CNT $(0.33 \pm 0.02$ in control vs. $0.36 \pm$ 0.08 in hypercapnic rats, $P=0.77)$ nor the $\operatorname{CCD}(0.28 \pm 0.01$ in control vs. $0.22 \pm 0.03$ in hypercapnic rats $P=0.10$ ) was the ratio of gold in the apical membrane to total cell gold modified by chronic hypoxic hypercapnia (Fig. 8). Since only three animals were studied in each group, however, we cannot exclude that a small change in trafficking would have gone undetected by this method.

The abundance of the vacuolar $H^{+}$-ATPase Bl subunit was unchanged in the cortex and outer medulla of hypercapnic rats. The vacuolar $\mathrm{H}^{+}$-ATPase in the $\mathrm{CCD}$ is situated in the apical membrane of type $A$ intercalated cells and in the basolateral membrane of type B intercalated cells. The B1 subunit is specifically associated with the $\mathrm{V}$-type proton pumps located in the CNT and collecting duct. There was no significant modification of the abundance of the B1 subunit of the proton pump between the groups in either homogenates of tissue from cortex/OSOM or ISOM as assessed by immunoblotting (Fig. 9).

ENaC subunits did not show changes in abundance or enhanced apical targeting. Since $\mathrm{ENaC}$ has been shown to be downregulated in metabolic acidosis induced by $\mathrm{NH}_{4} \mathrm{Cl}$ loading using a gelled diet (17), we performed immunoblotting and immunohistochemistry for the $\mathrm{ENaC}$ subunits. There were no significant changes in abundance of the $\alpha-, \beta-$, or $\gamma$ - subunits of $\mathrm{ENaC}$ (Fig. 10, $A$ and $B$ ) in cortex/OSOM homogenate. Immunochemistry can assess modification of trafficking of $\mathrm{ENaC}$ subunits, which is an important regulatory event for $\mathrm{ENaC}$. Immunohistochemistry for $\beta$ - and $\gamma$-ENaC did not reveal any obvious change in trafficking of these subunits (data not shown).

AQP2 abundance was unchanged in the two groups. We measured the abundance of AQP2 in the inner medulla and inner stripe of outer medulla of both groups by semiquantitative immunoblotting to further ensure that there was no volume depletion in the treated rats compared with controls. There was no significant difference in the abundance of the water channel in these two zones $(125 \pm 28$ vs. $100 \pm 11 \%$ in ISOM, $P=$ 0.42 and $119 \pm 15 \%$ in hypercapnic rats vs. $100 \pm 5 \%$ in control rats in IM, $P=0.24)$.

\section{DISCUSSION}

Rats exposed to hypoxic hypercapnia developed a partially compensated respiratory acidosis. Rats exposed to hypoxic hypercapnia presented a clear increase in their arterial $\mathrm{PCO}_{2}$ and a decrease in $\mathrm{Po}_{2}$. This confirmed the establishment of a mixed hypercapnia-hypoxemia model, mimicking a condition of respiratory failure. The plasma concentration of bicarbonate was 
Fig. 7. Immunoelectron microscopic appearance of pendrin-positive cells and subcellular localization of pendrin in the CNT of control rats $(A)$ and hypercapnic rats $(B)$ and in the CCDs of control $(C)$ and hypercapnic rats $(D)$. The labeling was observed in the apical plasma membrane and in intracellular structures of pendrin-positive cells in both control $(A$ and $C$ ) and hypercapnic rats $(B$ and $D)$. Arrows, immunogold-labeled pendrin. Scale bars $=5 \mu \mathrm{m}$ except for insets $(500 \mathrm{~nm})$.
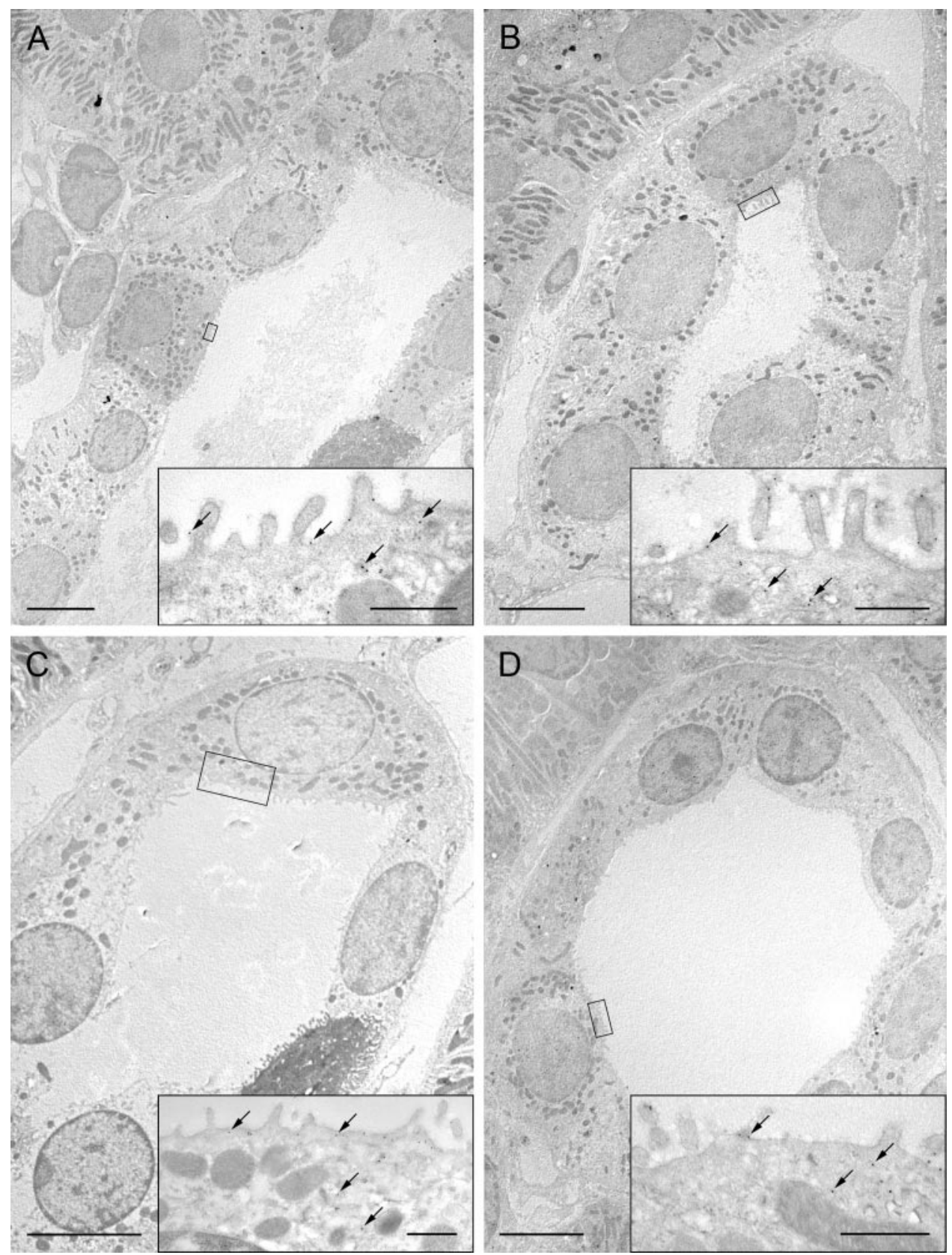

increased in hypercapnic rats, allowing for a slight decrease in $\mathrm{pH}$ only and confirming a state of partially compensated chronic respiratory acidosis. This is expected, since complete correction of $\mathrm{pH}$ is not observed in this condition (37). Given the blood-gas analysis, there was no apparent mixed acid-base disorder in these rats (37). Moreover, the hypoxemia in the treated group was relatively mild, as no lactate elevation was obvious in any of the groups. Therefore, from an acid-base point of view, our model is representative of a pure chronic compensated respiratory acidosis.

In this model, the plasma osmolality, the aldosterone level, and the abundance of $\mathrm{AQP} 2$ and $\mathrm{ENaC}$ proteins were unchanged, solid arguments against volume depletion and dehydration. We also observe a clear decrease in plasma chloride concentration in the treated animals. The decrease in plasma chloride is part of the response to respiratory acidosis and is of renal origin (23). In the classic view of acid-base physiology, the kidney is expected to compensate for a drop in $\mathrm{pH}$ induced by $\mathrm{CO}_{2}$ by retaining bicarbonate and increase proton secretion and the decreased plasma chloride is considered a side effect of the renal changes in proton and bicarbonate transport. According to the Stewart (38) approach, the $\mathrm{pH}$ is dependent on $\mathrm{PCO}_{2}$, strong ion difference, and concentrations of weak acids, and bicarbonate is not considered an independent determinant of $\mathrm{pH}$. Accordingly, chronic respiratory acidosis can be interpreted as an acidification due to an increase in $\mathrm{PCO}_{2}$, which the kidney compensates for by increasing the strong ion difference in the plasma, e.g., by increasing the excretion of chloride relative to sodium. Both theoretical approaches thus offer explanations of how the primary change in $\mathrm{PCO}_{2}$ is translated 
A

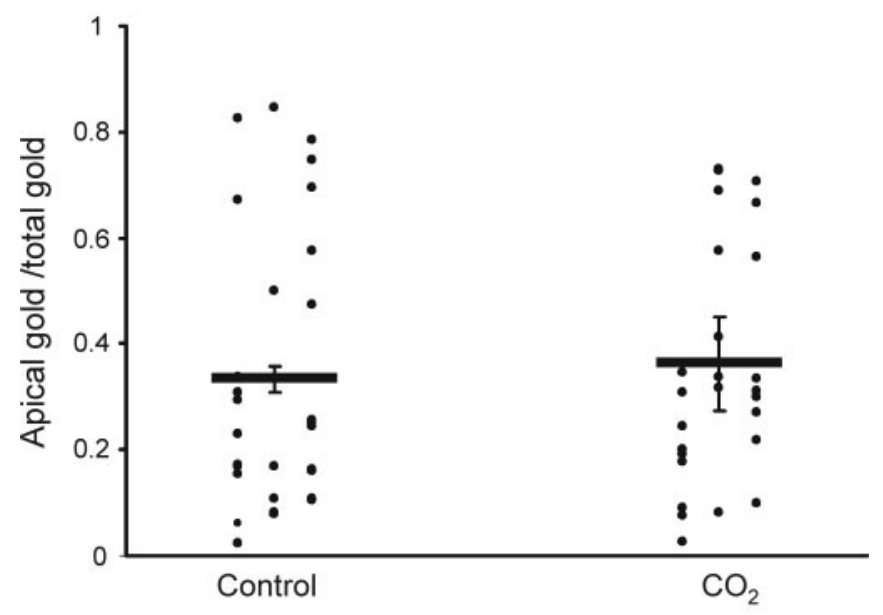

B

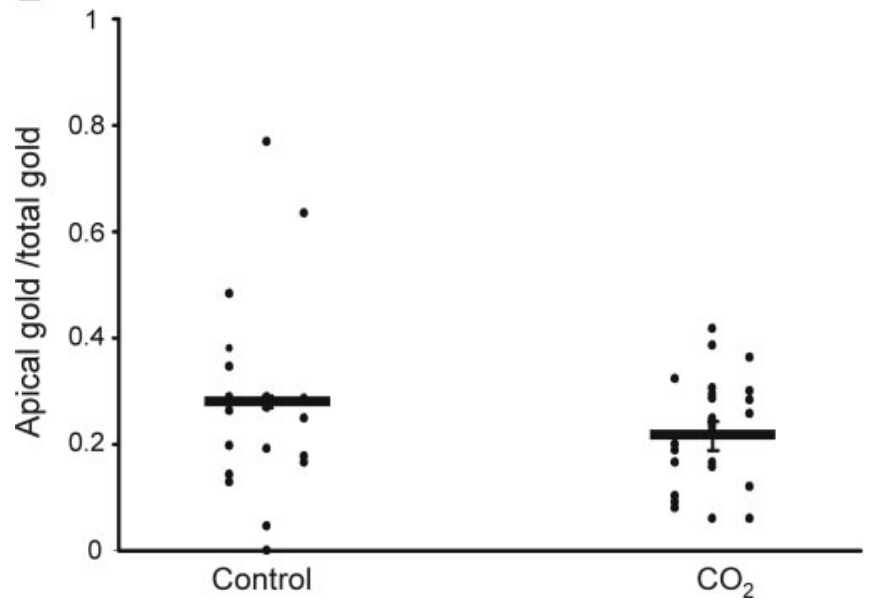

Fig. 8. Semiquantitative measurement of subcellular localization of pendrin. The ratio of the gold particles located on the apical membrane to the total gold particles counted in each cell is reported as a single data point. In each group, 3 animals were studied and a minimum of 6 pendrin-positive cells were counted in the CNT $(A)$ and the CCD $(B)$ of each animal. The mean in each animal was then computed, and the means of the animals in each group are shown as thick horizontal bars, with the error bars representing SE. No significant differences between the group means were detected $(P=0.77$ for CNTs and 0.10 for CCDs, respectively).

by the kidney into the observed changes in plasma bicarbonate and chloride levels. Since our model includes moderate hypoxemia, as observed in most natural and clinical situations of hypercapnia, it should be considered whether hypoxemia could account for all the adaptations observed. Although we cannot exclude some participation, we find it to be unlikely, since a more global profile of downregulation of membrane transporters would be expected in response to hypoxemia, e.g., as described in ischemic renal failure $(12,21)$.

The proximal tubule adapts to chronic respiratory acidosis. Evidence suggests that the proximal tubule plays a role in the increase in bicarbonate reabsorption and proton secretion in chronic hypercapnia (39). In our setting, total NHE3 protein abundance was not upregulated by chronic respiratory acidosis. However, this unchanged NHE3 abundance does not preclude the known increase in NHE3 activity $(32,39)$, since the specific activity of NHE3 may be regulated, e.g., by phosphor- ylation (49) and trafficking (47). We also did not address the V-ATPase in the proximal tubule, which also contributes to proton secretion in this segment.

NBCe1 is situated on the basolateral side of proximal tubule cells and mediates bicarbonate exit out of the proximal tubular cell mainly in S1 and S2 (35). The relative abundance of NBCe1 was clearly increased in the cortex/OSOM of hypercapnic rats relative to controls, and immunohistochemistry revealed this increase to take place in both S1 and S2 segments. An increased activity of NBCe1 also occurs in chronic hypercapnic rabbits (32), and an increased synthesis of NBCe1 is described in vitro using an immortalized proximal tubule cell line exposed to high $\mathrm{CO}_{2}$ levels for $12 \mathrm{~h}$ (9). This finding, however, is in contrast to the known unchanged abundance of $\mathrm{NBCe} 1$ in metabolic acidosis induced by $\mathrm{NH}_{4} \mathrm{Cl}$ loading (22). This difference might be linked to a specific regulatory pathway in respiratory acidosis.

In summary, in chronic respiratory acidosis, the proximal tubule seems to participate in renal compensation by increasing its absorption of bicarbonate through activation and increased expression of NBCe1, and activation of NHE3 independently of protein expression $(5,9,32,39)$.

Adaptation of the collecting duct to chronic respiratory acidosis. Compensation with regard to respiratory acidosis is characterized by a decrease in plasma chloride together with an increase in plasma bicarbonate. Increased bicarbonate reabsorption seems to take place partly in the proximal tubule, but

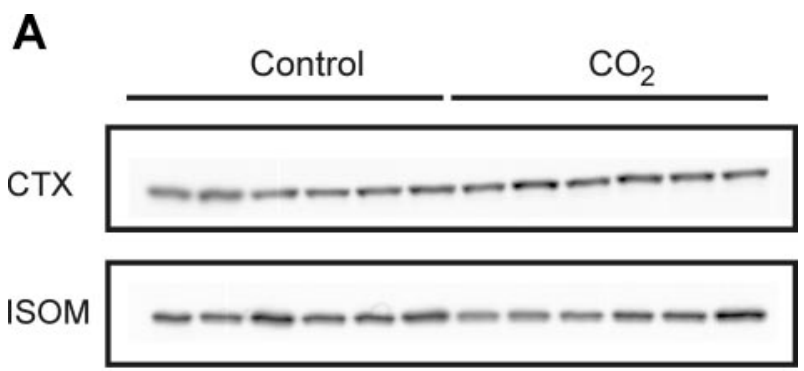

B
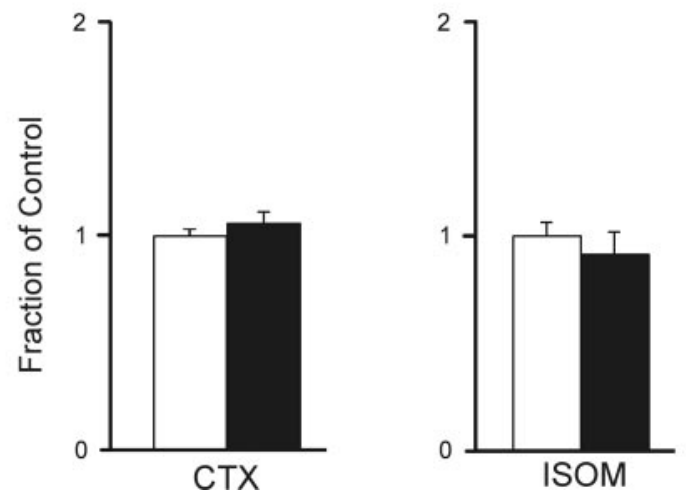

Fig. 9. Semiquantitative immunoblotting of homogenized rat kidney tissue from the cortex (CTX)/OSOM, and inner stripe of outer medulla (ISOM) from control and hypercapnic rats for the V1-ATPase B1 subunit. A: immunoblot of samples from control $(n=6)$ and hypercapnic $(n=6)$ rats incubated with anti-V1-ATPase B1 subunit antibody showing a distinct band at $\sim 62 \mathrm{kDa}$ in cortex/OSOM and ISOM. $B$ : densitometric analysis showed that the abundance of V1-ATPase B1 subunit in hypercapnic rats was unchanged in the cortex/ $\operatorname{OSOM}(P=0.37)$ and in the ISOM $(P=0.55)$ in hypercapnic rats (filled bars) compared with control rats (open bars). 
A
Control
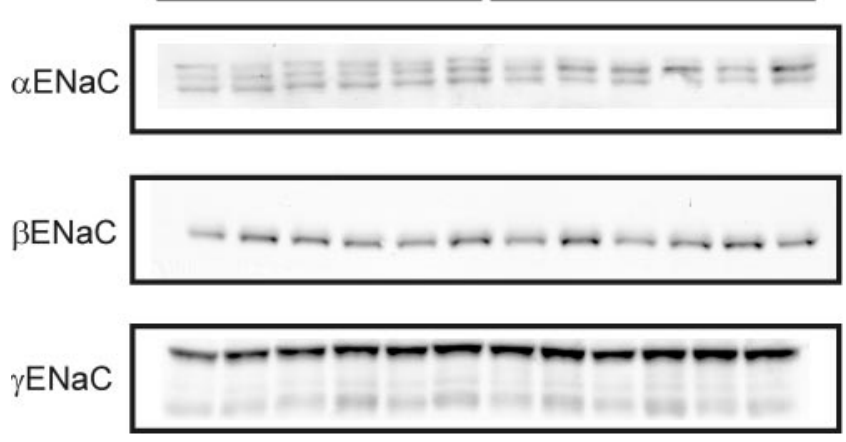

B

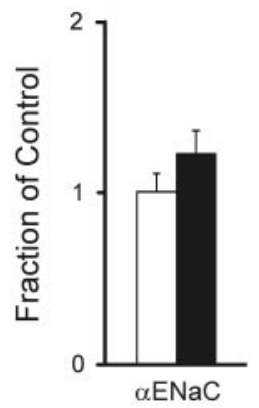

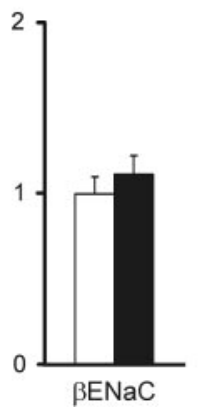

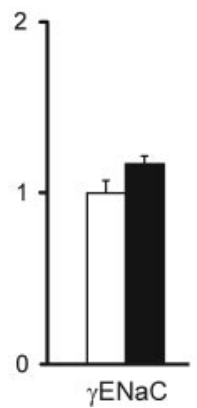

Fig. 10. Semiquantitative immunoblotting of homogenized rat kidney tissue from the cortex and OSOM from control and hypercapnic rats for $\alpha-, \beta-$, and $\gamma$-subunit of epithelial $\mathrm{Na}$ channel (ENaC). A: immunoblot of samples from control $(n=6)$ and hypercapnic $(n=6)$ rats incubated with $\alpha-, \beta-$, and $\gamma$ subunit of ENaC subunit antibody showing bands at $\sim 90 \mathrm{kDa}$ for $\alpha$ - and $\beta$-subunits and 90 and $70 \mathrm{kDa}$ for $\gamma$-subunit. $B$ : densitometric analysis showed that the abundance of $\alpha-, \beta$-, and $\gamma$-subunits of $\mathrm{ENaC}$ in hypercapnic rats were unchanged $(P=0.22, P=0.46$, and $P=0.13$, respectively) in hypercapnic rats (filled bars) compared with control rats (open bars) in cortex/OSOM.

it is unclear whether this is accompanied by decreased proximal tubular chloride reabsorption (5). In addition, the collecting duct is also likely to have a role in this compensation via regulation of intercalated cells. In chronic respiratory acidosis, the activity of the proton pump in the CCD and medullary collecting duct is increased (8), suggesting a role for type A intercalated cells in the generation of increased plasma bicarbonate and decreased plasma chloride. In the present study, the abundance of the B1 subunit of the proton pump was not modified. However, the proton pump may undergo cell typespecific expression regulation, which cannot be detected by immunoblotting. Furthermore, unchanged expression does not exclude activation of the pump (8), which, together with modification of subcellular localization (36), may be sufficient to increase acid secretion in the collecting duct as is described in metabolic acidosis (1).

The apical anion exchanger of type B intercalated cell, pendrin, is known to excrete bicarbonate and reabsorb chloride (31). As assessed by immunoblotting and immunohistochemistry, the abundance of pendrin was clearly decreased in the cortex of hypercapnic rats. The decreased labeling intensity was clearly apparent in both CNTs and CCDs, as assessed by laser and light microscopy, and was seen together with a reduction in the fraction of CCD cells showing immunoreactivity for pendrin. In addition to modifications of expression, pendrin has also been described to be regulated by changes in subcellular localization in mice $(43,44,46)$. In the present study, however, subcellular redistribution of pendrin was not obvious given the high variability between cells. Quantification of immunogold labeling using electron microscopy confirmed the large cell-to-cell variability and did not reveal significant differences in the fraction of membrane-associated pendrin in CNT nor CCD between the groups. Since only three animals were analyzed in each group by electron microscopy, however, it cannot be excluded that a difference of the magnitude observed could have been detected with statistical significance, notably in the CCD, if the number of animals studied had been higher. Furthermore, we did not differentiate the type $\mathrm{B}$ intercalated cells from the non-A non-B intercalated cells due to the lower abundance of this latter cell type in rats than in mice. Thus we cannot formally exclude that a cell type-specific regulation of trafficking occurred.

In any case, the $49 \%$ decrease in pendrin expression in the cortex, even without obvious changes in subcellular distribution, implies that the total abundance of pendrin in the apical membrane would also be decreased to $\sim 50 \%$ in hypercapnic rats compared with controls. Interestingly, the observed increased plasma bicarbonate and decreased plasma chloride are exactly the predicted effects of reduced pendrin activity, as could be anticipated to result from this reduced pendrin abundance. Therefore, the downregulation of pendrin may participate in redirecting the CNT and CCD toward excretion of chloride and reabsorption of bicarbonate. Together with an increased activity of A cells and the described adaptations of the proximal tubule, this event is likely to contribute to the observed plasma values.

Pendrin has also been described as playing a role in the distal tubular response to mineralocorticoids (43), but since no difference in aldosterone level was found here between the control and the hypercapnic group, the observed effect on pendrin expression was probably not mediated by this hormone. Moreover, no load of either sodium or chloride was imposed on the animals in this setting. In fact, hypercapnic animals even had a lower $\mathrm{NaCl}$ intake than controls due to lower food intake, which therefore cannot explain the observed downregulation of pendrin (46). Our data thus support that the downregulation of pendrin was seen in response to a primary respiratory acid-base equilibrium disturbance induced by hypercapnic hypoxemia.

Conclusion. We describe here the adaptation of the proximal tubule and the collecting duct to hypercapnia and hypoxia, mimicking a condition of chronic respiratory failure. The proximal tubule seems to play a role in the maintenance of high plasma bicarbonate levels as indicated by the increase in the abundance of NBCe1. The CNT and CCD appear also involved in the compensation as a clear reduction in the abundance of the anion exchanger pendrin was observed in response to chronic respiratory acidosis. In this study, pendrin was regulated independently of aldosterone levels and of chloride loading, revealing a potential direct effect of acid-base imbalance on the regulation of this protein. Finally, this downregulation of pendrin may contribute to generate and maintain the observed high plasma bicarbonate and low chloride level in chronic respiratory acidosis. 


\section{ACKNOWLEDGMENTS}

We thank Mogens Koed and Gøsta Dam Jensen for invaluable help in making the environmental chambers and Einar Larsen for construction of the electronic control system. We also thank Lotte Vallentin Holbech, Inger Merete Paulsen, Line V. Nielsen, Ida Jalk, Zhila Nikrozi, and Albert Meier for excellent multifaceted technical expertise and help. We warmly thank Arvid B. Maunsbach, Alicia McDonough, Mark Knepper, and Jeppe Prætorius for very helpful discussions.

\section{GRANTS}

This study was supported by the NOVO-Nordisk Foundation. The Water and Salt Research Center is established and supported by the National Danish Science Foundation. Sophie de Seigneux was supported by a Medicine and Biology grant (FSMB).

\section{REFERENCES}

1. Bastani B, Purcell H, Hemken P, Trigg D, Gluck S. Expression and distribution of renal vacuolar proton-translocating adenosine triphosphatase in response to chronic acid and alkali loads in the rat. $J$ Clin Invest 88: 126-136, 1991.

2. Bichara M, Paillard M, Leviel F, Gardin JP. Hydrogen transport in rabbit kidney proximal tubules-Na:H exchange. Am J Physiol Renal Fluid Electrolyte Physiol 238: F445-F451, 1980.

3. Bichara M, Paillard M, Leviel F, Prigent A, Gardin JP. Na:H exchange and the primary H pump in the proximal tubule. Am J Physiol Renal Fluid Electrolyte Physiol 244: F165-F171, 1983.

4. Christensen BM, Kim YH, Kwon TH, Nielsen S. Lithium treatment induces a marked proliferation of primarily principal cells in rat kidney inner medullary collecting duct. Am J Physiol Renal Physiol 291: F39_ F48, 2006

5. Cogan MG. Chronic hypercapnia stimulates proximal bicarbonate reabsorption in the rat. J Clin Invest 74: 1942-1947, 1984.

6. Duc C, Farman N, Canessa CM, Bonvalet JP, Rossier BC. Cell-specific expression of epithelial sodium channel alpha, beta, and gamma subunits in aldosterone-responsive epithelia from the rat: localization by in situ hybridization and immunocytochemistry. J Cell Biol 127: 1907-1921, 1994.

7. Ecelbarger CA, Kim GH, Terris J, Masilamani S, Mitchell C, Reyes I, Verbalis JG, Knepper MA. Vasopressin-mediated regulation of epithelial sodium channel abundance in rat kidney. Am J Physiol Renal Physiol 279: F46-F53, 2000.

8. Eiam-ong S, Laski ME, Kurtzman NA, Sabatini S. Effect of respiratory acidosis and respiratory alkalosis on renal transport enzymes. Am J Physiol Renal Fluid Electrolyte Physiol 267: F390-F399, 1994.

9. Espiritu DJ, Yang VL, Bernardo AA, Arruda JA. Regulation of renal $\mathrm{Na}^{+} / \mathrm{HCO}_{3}^{-}$cotransporter stimulation by $\mathrm{CO}_{2}$ : role of phosphorylation, exocytosis and protein synthesis. J Membr Biol 199: 39-49, 2004.

11. Fernandez-Llama P, Andrews P, Ecelbarger CA, Nielsen S, Knepper M. Concentrating defect in experimental nephrotic syndrome: altered expression of aquaporins and thick ascending limb $\mathrm{Na}^{+}$transporters. Kidney Int 54: 170-179, 1998.

12. Fernandez-Llama P, Andrews P, Turner R, Saggi S, Dimari J, Kwon TH, Nielsen S, Safirstein R, Knepper MA. Decreased abundance of collecting duct aquaporins in post-ischemic renal failure in rats. $J$ Am Soc Nephrol 10: 1658-1668, 1999.

13. Frische S, Kwon TH, Frøkiær J, Madsen KM, Nielsen S. Regulated expression of pendrin in rat kidney in response to chronic $\mathrm{NH}_{4} \mathrm{Cl}$ or $\mathrm{NaHCO}_{3}$ loading. Am J Physiol Renal Physiol 284: F584-F593, 2003.

14. Giebisch G, Berger L, Pitts RF. The extrarenal response to acute acid-base disturbances of respiratory origin. J Clin Invest 34: 231-245, 1955.

15. Gluck SL, Underhill DM, Iyori M, Holliday LS, Kostrominova TY, Lee BS. Physiology and biochemistry of the kidney vacuolar $\mathrm{H}^{+}$-ATPase. Annu Rev Physiol 58: 427-445, 1996.

16. Kim GH, Ecelbarger C, Knepper MA, Packer RK. Regulation of thick ascending limb ion transporter abundance in response to altered acid/base intake. J Am Soc Nephrol 10: 935-942, 1999.

17. Kim GH, Martin SW, Fernandez-Llama P, Masilamani S, Packer RK, Knepper MA. Long-term regulation of renal Na-dependent cotransporters and ENaC: response to altered acid-base intake. Am J Physiol Renal Physiol 279: F459-F467, 2000
18. Kim J, Kim YH, Cha JH, Tisher CC, Madsen KM. Intercalated cell subtypes in connecting tubule and cortical collecting duct of rat and mouse. J Am Soc Nephrol 10: 1-12, 1999.

19. Kim YH, Kwon TH, Frische S, Kim J, Tisher CC, Madsen KM, Nielsen S. Immunocytochemical localization of pendrin in intercalated cell subtypes in rat and mouse kidney. Am J Physiol Renal Physiol 283: F744-F754, 2002

20. Kregenow DA, Rubenfeld GD, Hudson LD, Swenson ER. Hypercapnic acidosis and mortality in acute lung injury. Crit Care Med 34: 1-7, 2006.

21. Kwon TH, Frøkiær J, Han JS, Knepper MA, Nielsen S. Decreased abundance of major $\mathrm{Na}^{+}$transporters in kidneys of rats with ischemiainduced acute renal failure. Am J Physiol Renal Physiol 278: F925-F939, 2000.

22. Kwon TH, Fulton C, Wang W, Kurtz I, Frøkiær J, Aalkjaer C, Nielsen S. Chronic metabolic acidosis upregulates rat kidney Na-HCO cotransporters $\mathrm{NBCn} 1$ and $\mathrm{NBC} 3$ but not NBC1. Am J Physiol Renal Physiol 282: F341-F351, 2002.

23. Levitin H, Branscome W, Epstein FH. The pathogenesis of hypochloremia in respiratory acidosis. J Clin Invest 37: 1667-1675, 1958.

24. Masilamani S, Kim GH, Mitchell C, Wade JB, Knepper MA. Aldosterone-mediated regulation of $\mathrm{ENaC}$ alpha, beta, and gamma subunit proteins in rat kidney. J Clin Invest 104: R19-R23, 1999.

25. Maunsbach AB. Observations on the segmentation of the proximal tubule in the rat kidney. Comparison of results from phase contrast, fluorescence and electron microscopy. J Ultrastruct Res 16: 239-258, 1966.

26. Maunsbach AB, Vorum H, Kwon TH, Nielsen S, Simonsen B, Choi I, Schmitt BM, Boron WF, Aalkjaer C. Immunoelectron microscopic localization of the electrogenic $\mathrm{Na} / \mathrm{HCO}_{3}$ cotransporter in rat and ambystoma kidney. J Am Soc Nephrol 11: 2179-2189, 2000.

27. McKinney TD, Davidson KK. Effects of respiratory acidosis on $\mathrm{HCO}_{3}^{-}$ transport by rabbit collecting tubules. Am J Physiol Renal Fluid Electrolyte Physiol 255: F656-F665, 1988.

28. Murer H, Hopfer U, Kinne R. Sodium/proton antiport in brush-bordermembrane vesicles isolated from rat small intestine and kidney. Biochem J 154: 597-604, 1976.

29. Nielsen S, Chou CL, Marples D, Christensen EI, Kishore BK, Knepper MA. Vasopressin increases water permeability of kidney collecting duct by inducing translocation of aquaporin-CD water channels to plasma membrane. Proc Natl Acad Sci USA 92: 1013-1017, 1995.

30. Quentin F, Chambrey R, Trinh-Trang-Tan MM, Fysekidis M, Cambillau M, Paillard M, Aronson PS, Eladari D. The $\mathrm{Cl}^{-} / \mathrm{HCO}_{3}^{-}$exchanger pendrin in the rat kidney is regulated in response to chronic alterations in chloride balance. Am J Physiol Renal Physiol 287: F1179_ F1188, 2004

31. Royaux IE, Wall SM, Karniski LP, Everett LA, Suzuki K, Knepper MA, Green ED. Pendrin, encoded by the Pendred syndrome gene, resides in the apical region of renal intercalated cells and mediates bicarbonate secretion. Proc Natl Acad Sci USA 98: 4221-4226, 2001.

32. Ruiz OS, Arruda JA, Talor Z. Na- $\mathrm{HCO}_{3}$ cotransport and $\mathrm{Na}-\mathrm{H}$ antiporter in chronic respiratory acidosis and alkalosis. Am J Physiol Renal Fluid Electrolyte Physiol 256: F414-F420, 1989.

33. Ruiz OS, Talor Z, Arruda JA. Regional localization of renal $\mathrm{Na}^{+}-\mathrm{H}^{+}$ antiporter: response to respiratory acidosis. Am J Physiol Renal Fluid Electrolyte Physiol 259: F512-F518, 1990.

34. Santella RN, Maddox DA, Gennari FJ. Delivery dependence of early proximal bicarbonate reabsorption in the rat in respiratory acidosis and alkalosis. J Clin Invest 87: 631-638, 1991.

35. Schmitt BM, Biemesderfer D, Romero MF, Boulpaep EL, Boron WF. Immunolocalization of the electrogenic $\mathrm{Na}^{+}-\mathrm{HCO}_{3}^{-}$cotransporter in mammalian and amphibian kidney. Am J Physiol Renal Physiol 276: F27-F38, 1999.

36. Schwartz GJ, Al-Awqati Q. Carbon dioxide causes exocytosis of vesicles containing $\mathrm{H}^{+}$pumps in isolated perfused proximal and collecting tubules. J Clin Invest 75: 1638-1644, 1985.

37. Schwartz WB, Brackett NC Jr, Cohen JJ. The response of extracellular hydrogen ion concentration to graded degrees of chronic hypercapnia: the physiologic limits of the defense of pH. J Clin Invest 44: 291-301, 1965.

38. Stewart PA. Independent and dependent variables of acid-base control. Respir Physiol 33: 9-26, 1978.

39. Talor Z, Yang WC, Shuffield J, Sack E, Arruda JA. Chronic hypercapnia enhances $V_{\max }$ of $\mathrm{Na}-\mathrm{H}$ antiporter of renal brush-border membranes. Am J Physiol Renal Fluid Electrolyte Physiol 253: F394-F400, 1987. 
40. Tsuruoka S, Schwartz GJ. Adaptation of rabbit cortical collecting duct $\mathrm{HCO}_{3}^{-}$transport to metabolic acidosis in vitro. J Clin Invest 97: 10761084, 1996.

41. Tsuruoka S, Schwartz GJ. Metabolic acidosis stimulates $\mathrm{H}^{+}$secretion in the rabbit outer medullary collecting duct (inner stripe) of the kidney. J Clin Invest 99: 1420-1431, 1997.

42. Vallet M, Picard N, Loffing-Cueni D, Fysekidis M, Bloch-Faure M, Deschenes G, Breton S, Meneton P, Loffing J, Aronson PS, Chambrey R, Eladari D. Pendrin regulation in mouse kidney primarily is chloridedependent. J Am Soc Nephrol 17: 2153-2163, 2006.

43. Verlander JW, Hassell KA, Royaux IE, Glapion DM, Wang ME, Everett LA, Green ED, Wall SM. Deoxycorticosterone upregulates PDS (Slc26a4) in mouse kidney: role of pendrin in mineralocorticoid-induced hypertension. Hypertension 42: 356-362, 2003.

44. Verlander JW, Kim YH, Shin W, Pham TD, Hassell KA, Beierwaltes WH, Green ED, Everett L, Matthews SW, Wall SM. Dietary $\mathrm{Cl}^{-}$restriction upregulates pendrin expression within the apical plasma membrane of type B intercalated cells. Am J Physiol Renal Physiol 291: F833-F839, 2006.
45. Wagner CA, Finberg KE, Stehberger PA, Lifton RP, Giebisch GH, Aronson PS, Geibel JP. Regulation of the expression of the $\mathrm{Cl}^{-}$/anion exchanger pendrin in mouse kidney by acid-base status. Kidney Int 62 : 2109-2117, 2002.

46. Wall SM, Kim YH, Stanley L, Glapion DM, Everett LA, Green ED, Verlander JW. $\mathrm{NaCl}$ restriction upregulates renal Slc26a4 through subcellular redistribution: role in $\mathrm{Cl}^{-}$conservation. Hypertension 44: 982 987, 2004.

47. Yang LE, Maunsbach AB, Leong PK, McDonough AA. Differential traffic of proximal tubule $\mathrm{Na}^{+}$transporters during hypertension or PTH: NHE3 to base of microvilli vs. NaPi2 to endosomes. Am J Physiol Renal Physiol 287: F896-F906, 2004.

48. Zeidel ML, Seifter JL. Regulation of $\mathrm{Na} / \mathrm{H}$ exchange in renal microvillus vesicles in chronic hypercapnia. Kidney Int 34: 60-66, 1988.

49. Zhao H, Wiederkehr MR, Fan L, Collazo RL, Crowder LA, Moe OW. Acute inhibition of $\mathrm{Na} / \mathrm{H}$ exchanger $\mathrm{NHE}-3$ by cAMP. Role of protein kinase a and NHE-3 phosphoserines 552 and 605. J Biol Chem 274: 3978-3987, 1999.

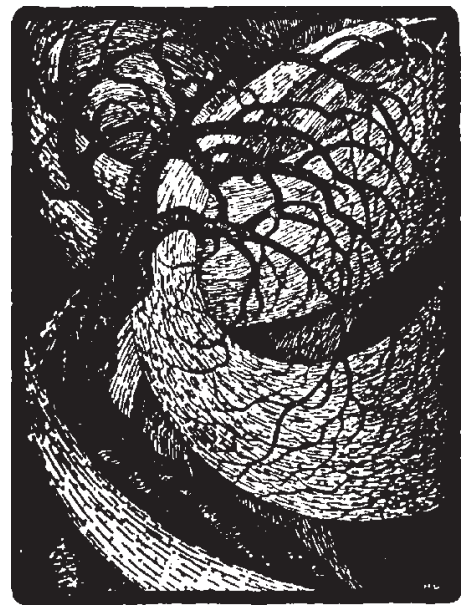

